\title{
Treatment of asthma in a general practice
}

\author{
C. D. SHEE* \\ M.B., M.R.C.P.
}

D. POOLE

M.B., Ch.B.

\author{
I. R. CAMERON \\ D.M., F.R.C.P. \\ Department of Medicine, St Thomas's Hospital Medical School, London SEI
}

\begin{abstract}
Summary
We examined the general practice treatment of 67 patients diagnosed as asthmatic. Compliance with treatment was poor in one-third of patients with severe asthma. Inhaled steroids were under-prescribed and our findings suggest that some severe asthmatics are receiving less than adequate therapy.
\end{abstract}

KEY WORDS: corticosteroid therapy, patient compliance, peak flow rate, spirometry.

\section{Introduction}

Many asthmatics may be receiving inadequate treatment (Seaton, 1978; Speight, Lee and Hey, 1983). Despite recent advances in drug therapy, it appears that some asthmatics, although correctly diagnosed, are left with severe airflow limitation which relatively simple treatment could reverse. We have examined the possibility that this may be so in a general practice.

\section{Patients and methods}

The study was undertaken in a five-partner practice in south-east London. There was no practice register of asthmatics, and from 12,500 case notes we identified 117 patients aged between 16-70 years with a written diagnosis of 'asthma' in the notes. Notes in which terms such as 'wheezy bronchitis', 'reversible airways obstruction' or 'wheeze' had been used were rejected. This method of selection will underestimate the prevalence of the disease, but the main interest was in the treatment of patients labelled as asthmatic. A letter, signed by a general practitioner, and containing a pre-stamped reply envelope, was sent to each patient. If necessary two further letters were sent and, where possible, a telephone call made. Only 67

\footnotetext{
*Present address: Meakins-Christie Laboratories, 3775 University Street, Montreal, Quebec, H3A 2B4, Canada.
}

patients $(57 \%)$ participated. Twenty-one patients refused to participate and nine failed to attend practice appointment having agreed to do so. Twent\$ patients did not reply to the letters and could not be contacted via the telephone. It is likely that many o\$ these patients had moved, as the practice is in an area with a very mobile population.

Patients were interviewed and a modified M.R.C? questionnaire completed. Spirometry (Vitalograph and peak expiratory flow rate (PEFR-Wright pea flow meter) were measured before and $10 \mathrm{~min}$ after $200 \mu \mathrm{g}$ of salbutamol by inhalation. Predicted valoes are from Cotes (1975). Results are presented as percentage of total predicted and as the mean \pm s.e.m. Skin prick tests to four common allergen and control were performed and for 1 week patient recorded home PEFR on a diary card.

\section{Results}

Sixty-seven patients attended ( 36 female, 31 male)? The mean age was 36 years, $20(30 \%)$ were curren⿳亠丷厂 cigarette smokers and $51(76 \%)$ had one or more positive skin tests. The mean forced expiratory. volume in $1 \mathrm{sec}\left(\mathrm{FEV}_{1}\right)$ was $66 \pm 3 \%$ predicted witts $18 \pm 2 \%$ reversibility and the mean PEFR was. $72 \pm 3 \%$ predicted. Seventeen patients $(25 \%)$ claime never to have been told they had asthma. Forty-one patients $(61 \%)$ regularly used inhalers but nine of these $(22 \%)$ were unable to use them correctly.

Twenty-one patients had a FEV 1 below 55\% predicted, indicating severe airflow limitatio (Group I). Forty-six patients had an FEV 1 equal to oP over $56 \%$ predicted (Group II). There was goodu agreement between initial FEV and PEFR readingsu The mean FEV 1 in Group I was $35 \pm 3 \%$ (PEFB $42 \pm 4 \%$ ) and in Group II was $88 \pm 2 \%$ (PEFR $86 \pm 3 \%$ ). Home PEFR monitoring showed the exe pected diurnal variation with lower readings in the morning than in the evening (Group I, 38\% v. $44 \%$; 
Group II, $77 \%$ v. $81 \%$ ). Group I had more frequent and severe wheezing attacks than Group II and estimated their breathlessness and disability as greater. Ten patients in Group I had a chronic cough and 10 were stopped by breathlessness when walking at their own pace. Treatment, as judged by symptoms and lung function during observation, was adequate in Group II. This was not so for Group I and the treatment recorded is shown in Table 1.

TABLE 1. Treatment being received by 21 symptomatic patients with an $\mathrm{FEV}_{1}$ below $55 \%$ predicted (Group I)

No treatment

Bronchodilator only

Bronchodilator + inhaled steroid

Bronchodilator + inhaled steroid + oral steroid

Bronchodilator + disodium cromoglycate + oral steroid

In spite of severe symptoms and poor lung function, regular treatment with steroids (inhaled or oral) or disodium cromoglycate (DSCG) was used by only 11 patients $(52 \%)$ in Group $I$. The remaining patients received a bronchodilator only (nine patients) or no treatment (one patient).

\section{Discussion}

We have studied a sample of 67 patients with asthma from a practice population of $12,500(0 \cdot 5 \%)$. This sample will underestimate the prevalence of asthma because of the age restriction applied, insistence that the written diagnosis should use the word 'asthma' and because of limited patient co-operation. Our interest was not in the prevalence of asthma but in the disability and treatment of those diagnosed as asthmatic. After a firm diagnosis of asthma has been made, treatment should be aimed at obtaining the best results for lung function and symptoms within the limits of an acceptable drug regime. If symptoms and airflow limitation persists on a simple bronchodilator regime we would expect to find that a regular prophylactic drug had been used, such as DSCG, inhaled or oral steroids (Editorial, 1979). In Group 1, 21 asthmatics who were symptomatic with poor lung function, this expectation was not fulfilled. Nine patients $(43 \%)$ received no treatment apart from a bronchodilator and one patient no treatment at all. Two patients were using DSCG (although nine had a strong history of atopy) and 10 (48\%) were receiving neither oral nor inhaled steroids. All patients were known asthmatics and it was considered that in at least seven patients the major reason for inadequate treatment was that the doctor had failed to appreciate the severity of the disease. We excluded children from our survey, but there is evidence that childhood asthma is underdiagnosed and undertreated (Speight et al., 1983; Anderson et al., 1981). Parents are often not told the diagnosis, bronchodilators and prophylactic treatment are underused and the use of inappropriate drugs is common. Our study suggests that in adults too, unsatisfactory treatment may be widespread. In Melbourne, Australia, in a group of asthmatics aged 21 years with severe or persistent wheeze, $20 \%$ were receiving no medical care and $41 \%$ inappropriate treatment (Martin, Landau and Phelan, 1982). In a recent study of 90 asthma deaths, a British Thoracic Association (BTA) Panel reviewed treatment in the year preceding death and concluded that maintenance therapy was unsatisfactory in $61 \%$ of patients (British Thoracic Association, 1982). Stellman, Spicer and Cayton (1982) have reviewed the response to treatment of asthma patients referred to a hospital clinic. They found that pre-referral treatment was often inadequate and that asthma had not been diagnosed in one-third of patients referred. With greater use of inhaled bronchodilators and inhaled steroids most patients improved (Stellman $e t$ al., 1982).

It is not only doctors who are responsible for unsatisfactory treatment. Patients too can ignore their asthma. Some patients may not detect deteriorating asthma (Rubinfeld and Pain, 1976), but in our study seven asthmatics with severe symptoms had repeatedly failed to renew their prescriptions or to visit the doctor as requested. Similarly, the 1982 BTA study of asthma deaths found that only $47 \%$ of patients had co-operated fully with their treatment. We conclude that many asthmatics are receiving inadequate treatment and that a failure or reluctance to use steroids is common.

\section{References}

ANderson, H.R., Balley, P.A., CoOPer, J.S. \& PAlmeR, J.C. (1981) Influence of morbidity, illness label, and social, family and health service factors on drug treatment of childhood asthma. Lancet, ii, 1030.

BRITISH THORACIC AsSOCIATION (1982) Death from asthma in two regions of England. British Medical Journal, 285, 1251.

COTES, J.E. (1975) Lung Function: Assessment and application in Medicine. 3rd edn. Blackwell Scientific Publications, Oxford.

EDITORIAL (1979) Saving asthmatics. British Medical Journal, I, 1520.

Martin, A.J., Landau, L.I. \& Phelan, P.D. (1982) Asthma from childhood at age 21: the patient and his disease. British Medical Journal, 284, 380.

Rubinfeld, A.R. \& Pain, M.C.F. (1976) Perception of asthma Lancet, i, 882.

Seaton, A. (1978) Asthma-contrasts in care. Thorax, 33, 1.

SPEIGHT, A.N.P., LEE, D.A. \& HEY, E.N. (1983) Underdiagnosis and undertreatment of asthma in childhood. British Medical Journal, 286, 1253

Stellman, J.L., SPICER, J.E. \& CaYton, R.M. (1982) Morbidity from chronic asthma. Thorax, 37, 218.

(Accepted 11 October 1983) 